\title{
Seismic performance of a masonry arch viaduct subjected to foreshocks and a mainshock
}

\author{
Izabela J. Drygala ${ }^{1, *}$, Joanna M. Dulinska ${ }^{1}$, Lukasz Bednarz ${ }^{2}$, and Jerzy Jasienko ${ }^{2}$ \\ ${ }^{1}$ Cracow University of Technology, Warszawska 24, 31-155 Krakow, Poland \\ ${ }^{2}$ Wroclaw University of Science and Technology, Plac Grunwaldzki 11, 50-377 Wroclaw, Poland
}

\begin{abstract}
The main objective of this work is to present the results of seismic numerical investigation which was conducted for a masonry arch viaduct. The viaduct which was chosen as a case study, was subjected to foreshock-mainshock sequence. For the numerical evaluation a 3D finite element model (FEM) of the structure was assembled with the ABAQUS/Standard software program. In the numerical simulations a Barcelona Model (BM) was applied as a constitutive material model to represent nonlinear behaviour of the masonry arches of the investigated viaduct under the seismic actions. Taken into consideration the results of calculations the evident nonlinear behaviour of the masonry arches was detected under the earthquakes. The plastic strains as well as the cracking were achieved in some areas of the arches of the viaduct after seismic foreshock-mainshock sequence. Also proposed methodology for strengthening and monitoring of the structure of the viaduct in the future.
\end{abstract}

\section{Introduction}

The studies of damages of masonry arch type bridge caused by strong seismic loading have revealed that the protection of these structures turned out to be an important technical task. Especially for monumental masonry bridges erected on seismic activity areas, the dynamic loading caused by earthquake is one of the most destruction factor [1, 2, 3]. It must be pointed out, that the vast majority of seismic mainshocks are usually preceded by various foreshocks within a short period of time [4]. Considering the mechanism of earthquake loadings, it is strictly reasonable to consider full sequence of seismic events which may load the structure. The dynamic response of different types of structures subjected to earthquake sequence has been extensively studied recently. Taken into considaration the evaluation procedures which were presented by different authors $[5,6,7,8]$, the numerical detection of damages in structures subjected to seismic loadings is very important and significant stage. In particular, the numerical simulations with nonlinear material models deliver good quality data for future project of the reinforcement of the structural elements which are threatened [9].

In this work the numerical evaluation of damages of masonry arch viaduct subjected to foreshock-mainshock seismic sequence is presented. The masonry arch type viaduct located in Krakow (Southern Poland) was chosen as a case study [10]. The structure was subjected to foreshock-mainshock earthquakes sequence which were recorded in central Italy, i.e.

\footnotetext{
*Corresponding author: idrygala@pk.edu.pl
} 
Marche region in 2016 [11]. In order to assessment the influence of the strong seismic events on the studied viaduct, the Barcelona Model (BM) also known as the concrete damage plasticity model (CDP) of material was implemented [12]. This aproach made possible to evaluated different types of damages as well as plasticisation which accured due to full foreshock-mainshock sequence.

\section{FE model of the viaduct and methods of the investigation}

The studied masonry arch bridge (see Fig. 1a), which was chosen as a case study, was erected in Krakow (southern Poland) in the years 1861-1863. The primary purpose of the viaduct was to conduct the railway above the old riverbed of the Vistula river. Since the old riverbed was buried, the bridge works as a viaduct above the road. It must be pointed out that the studied viaduct is one of the oldest bridges in this part of southern Poland. The structure of the bridge was designed as five masonry arches with a span equal to $14.4 \mathrm{~m}$. The bridge was built with two types of materials, i.e. stone and masonry elements [10].

For the study aims a finite element (FE) model of the structure was assembled with the ABAQUS/Standard software program. The 3D FE model was prepared as a numerical model with the quadratic hexahedral elements of the type C3D20R. The total number of nodes and elements equalled 350498 and 71820, respectively. The FE model of the viaduct is shown in Fig. 1b. For the masonry parts of the studied structure the non-linear material model was used since the main purpose of the numerical simulations was the evaluation of seismic-induced damages of the arches. As it was pointed out previously, the calculations were conducted in ABAQUS/Standard software program. For the masonry arches the concrete damage plasticity model (CDP), also known as the Barcelona Model (BM) was used [12, 13, 14]. The $\mathrm{CDP}(\mathrm{BM})$ is dedicated to concrete structural parts and it represents the isotropic character of this material. The fundamental assumption of the CDP (BM) is based on the mechanism of failure, i.e. tensile cracking and compressive crushing of the material. The behaviour of masonry structural elements is different than reinforcement concrete elements (masonry is anisotropic material). The main assumption for using BM for masonry structures were presented in $[13,14]$. For the stone parts of the structure the material parameters were assumed as follows: $\mathrm{E}=10.00 \mathrm{GPa}$ (elasticity modulus), $\rho=2300 \mathrm{~kg} / \mathrm{m}^{3}$ (mass density) and $\nu=0.18$ (Poisson's ratio) [10]. For the study purposes, the essential parameters of the BM for the masonry arches of the structure were adopted on the basis of literature as follows: $\mathrm{E}=9.48 \mathrm{GPa}, \rho=1800 \mathrm{~kg} / \mathrm{m}^{3}, \nu=0.16, \mathrm{f}_{\mathrm{c}}=12.30 \mathrm{MPa}$ (compressive strength), $\mathrm{f}_{\mathrm{t}}=2.00 \mathrm{MPa}$ (tensile strength) and $\varphi=38^{\circ}$ (dilation angle) $[9,10,15,16,17]$.
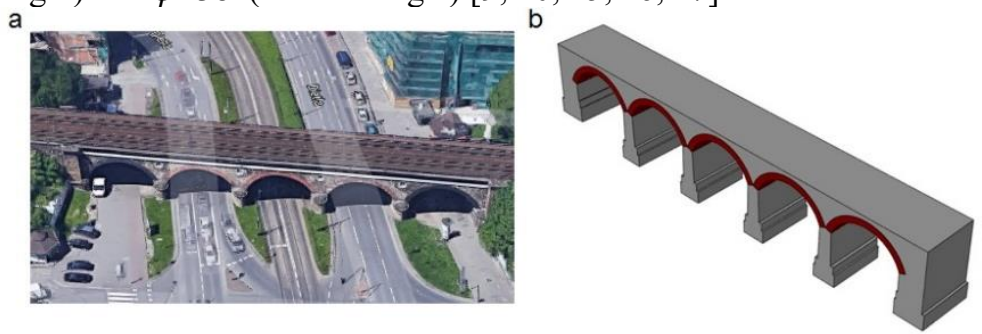

Fig. 1. The investigated masonry arch viaduct: a) view of the structure, b) FE model.

In the numerical dynamic analysis, earthquakes registered in Marche region (central Italy) were applied as kinematic excitations of the structure [11]. The Richter magnitude $\left(M_{L}\right)$ of the mainshock equalled 6.1, whereas the $M_{L}$ of the $1^{\text {st }}$ and $2^{\text {nd }}$ foreshock equalled to 5.4 and 5.9 , respectively. Time histories of accelerations of the investigated sequence of seismic events in three directions are presented in Figure 2. The peak ground accelerations (PGA) of the shocks are summarized in Table 2. 


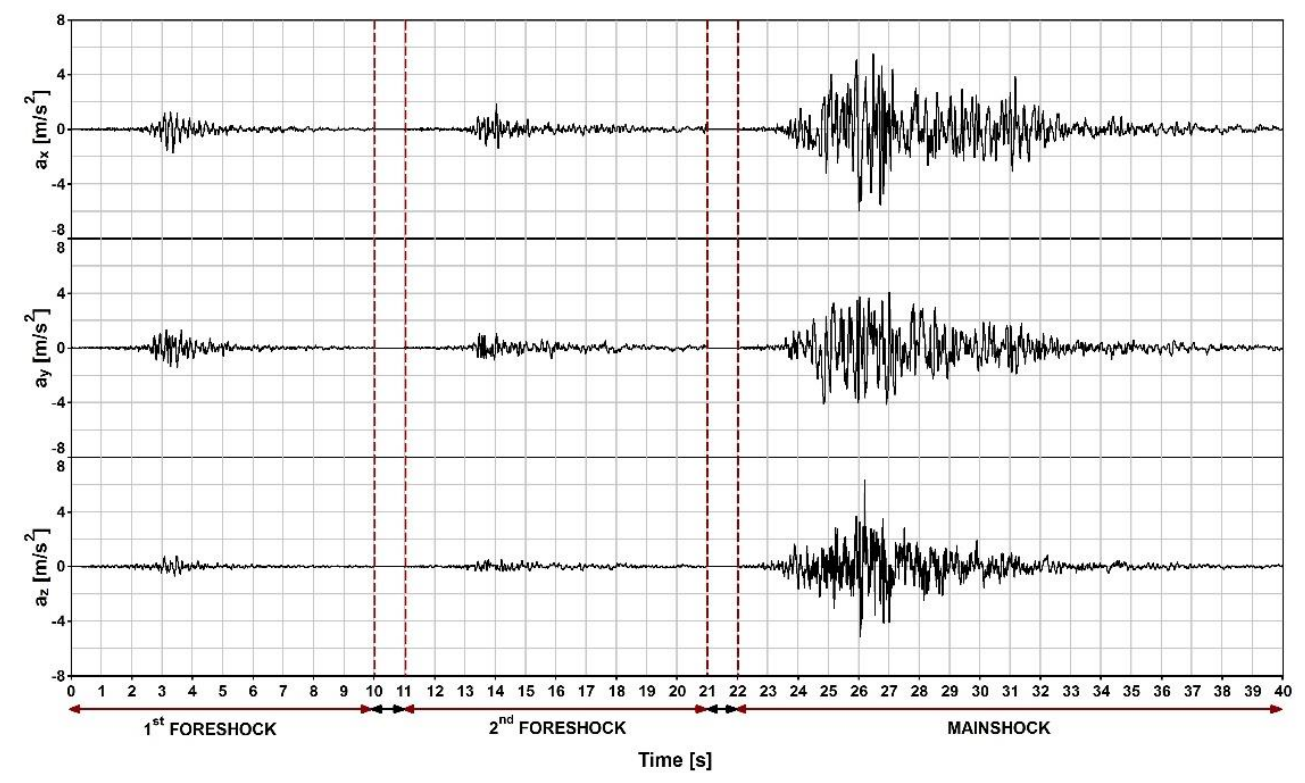

Fig. 2. Time histories of acceleration of the foreshock-mainshock sequence [11].

Table 2. The peak ground accelerations (PGA) of the seismic sequence events [11].

\begin{tabular}{|c|c|c|c|c|}
\hline \multirow{2}{*}{$\begin{array}{l}\text { Seismic } \\
\text { event }\end{array}$} & \multirow{2}{*}{ Date } & \multicolumn{3}{|c|}{$\begin{array}{l}\text { The peak ground accelerations (PGA) } \\
{\left[\mathrm{m} / \mathrm{s}^{2}\right]}\end{array}$} \\
\hline & & East-West & $\begin{array}{l}\text { North- } \\
\text { South }\end{array}$ & Up-Down \\
\hline $1^{\text {st }}$ foreshock & $\begin{array}{l}2016-10-26 \\
17: 10: 36\end{array}$ & 1.74 & 1.42 & 0.76 \\
\hline $2^{\text {nd }}$ foreshock & $\begin{array}{l}\text { 2016-10-26 } \\
19: 18: 06\end{array}$ & 1.84 & 1.09 & 0.54 \\
\hline mainshock & $\begin{array}{c}2016-10-30 \\
06: 40: 18\end{array}$ & 5.93 & 4.12 & 6.32 \\
\hline
\end{tabular}

The dynamic performance of the structure to all studied seismic events was performed using full-time history analysis. It was conducted with the Hilber-Hughes-Taylor time integration algorithm provided in the ABAQUS/Standard software for a direct step-by-step solution. The step varied from $10^{-5}$ to $10^{-2} \mathrm{~s}$, according to convergence requirements since the progressive damage and failure model of masonry elements implements strong material nonlinearity. In the numerical simulations, the time shift between the $1^{\text {st }}, 2^{\text {nd }}$ foreshocks and mainshock was equal to $1 \mathrm{~s}$ and was realized as a quasi-static step implemented by implicit dynamic analysis [18]. In this way, the complete unloading of the structure, between investigated seismic events, was accomplished. The Rayleigh model of damping was used for the numerical simulations. Damping ratio values were adopted for masonry bridges [10]. For the Rayleigh model of damping coefficients $\alpha$ (for mass proportional damping) and $\beta$ (for stiffness proportional damping) were used. The coefficients $\alpha=2.7391$ and $\beta=0.0009$ were estimated for damping ratios of $5.0 \%$ for the first $(7.84 \mathrm{~Hz})$ and the third $(9.83 \mathrm{~Hz})$ natural frequencies, i.e. for the first two frequencies which refer to modes shapes in horizontal directions. Such coefficients of damping were specified as the properties of material since ABAQUS/Standard software program provides this as a part of the material definition [18]. 


\section{Results discussion}

As measurements of destruction of masonry arches of the investigated viaduct the time histories of BM the following variables were applied: LEP (principal logarithmic strain), PEEQT (tensile equivalent plastic strain), DAMAGET (tensile damage variable), PEEQ (compressive equivalent plastic strain), DAMAGEC (compressive damage variable), SDEG (stiffness degradation variable). The distributions of the BM variables of the masonry arches are presented in Figs. 3 and 4, as a final result of the calculations. It can be noticed that the first zone of plasticization of the masonry arch was reported after the $1^{\text {st }}$ foreshock (see Fig. 3a). After the $2^{\text {nd }}$ foreshock, the first zone of plasticization increased and also some new areas were plasticized (see Fig. 3b). However, the most visible zones of plasticization were noticed after the full sequence of seismic events (see Fig. 3c). It must be pointed out that the total loss of stiffness appeared after the mainshock that is clearly visible in Fig. 4.

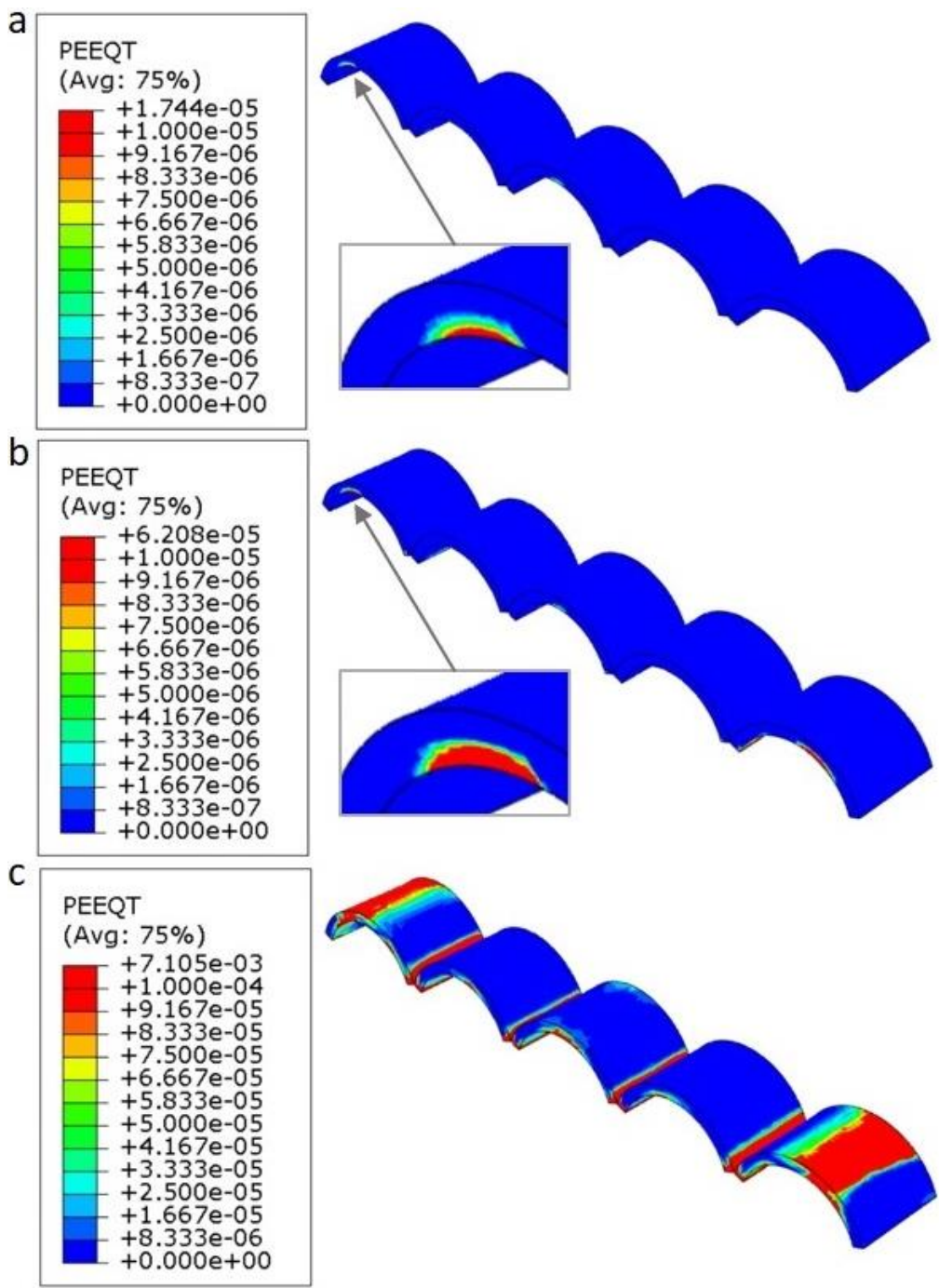

Fig. 3. Tensile equivalent plastic strain (PEEQT) due to : a) $1^{\text {st }}$ foreshock, b) $2^{\text {nd }}$ foreshock and c) mainschock. 
Taking into consideration of the results of the numerical simulations, especially the propagation of the destruction of the masonry arches of the viaduct due to the full foreshockmainshock sequence (see Fig. 4), the preparation of the proposal of strengthening is possible. The historical value of the bridge as well as the type of the investigated viaduct caused that techniques which would allow the least possible intervention in the historical tissue of the structure are recommended. The improvement of earthquake and quasi-earthquake resistance of masonry parts of the viaduct with strengthening systems can be realized by application composite materials. Composite materials in general and Fibre Reinforced Cementitious Matrix (FRCM), i.e. composites without epoxy resins, in particular have properties which increase a structural ductility not increasing a structural mass. This type of reinforcing materials are easy to install as well as they are environmental friendly. Detailed descriptions of the use and application of the FRCM composites materials can be found in [19].

The SHM methodology should include an initial survey and a visual assessment, especially of the zones with the highest number of damages. Monitoring of long-time structural behaviour of repaired and reinforced structures can be done not only by traditional geodetic methods. It can be done also using optical method of image correlation or using 3D laser scanner $[20,21]$. With that methods it is possible to document the actual status of heritage structures in a way that is highly accurate, not so time-consuming, allows for a description of the whole surface area, not just measurements of individual points as is the case in other geodetic methods. Only regular structure measurements show possible changes in the geometry of the heritage structure.

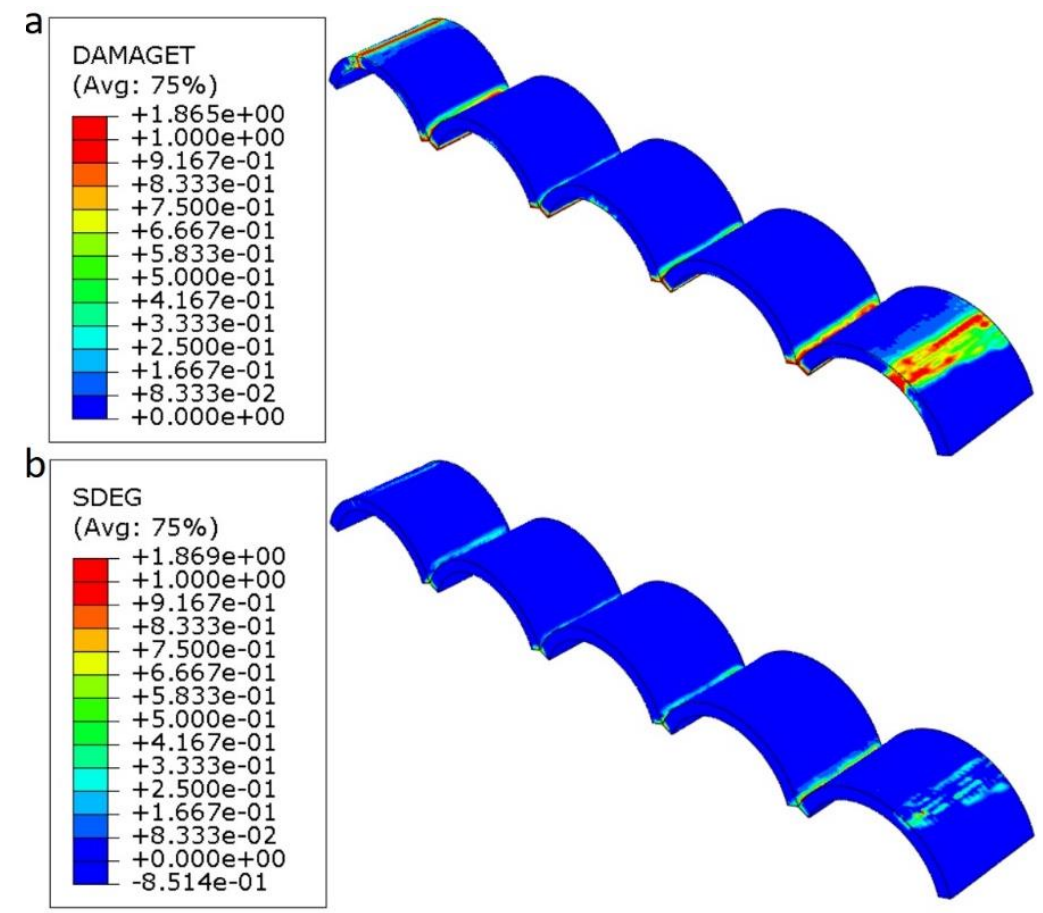

Fig. 4. Distribution of the BM variables due to the full foreshock-mainshock sequence: a) tensile damage variable (DAMAGET), b) stiffness degradation variable (SDEG). 


\section{Conclusions}

The main purpose of the presented research was a numerical evaluation of damages of the monumental masonry arch viaduct subjected to the full foreshock-mainshock sequence. The numerical procedures with the Barcelona Model of material were conducted with ABAQUS/Standard software.

Referring to results of the study, it is clearly visible that the numerical simulations with the non-linear material models are efficient and practical tools. Taken into consideration the results (see Fig. 3-6), it is possible to prepare the proposal of strengthening of the structure as well as the SHM methodology.

The presented analysis proved that the foreshock-mainshock sequence can cause substantial damages in structural parts of the investigated viaduct. The distribution of plastic strain and damages allowed to assess the impact of the full foreshock-mainshock sequence on masonry arches of the viaduct. It must be pointed out, that the first zone of plasticization of the masonry arch of the viaduct was reported already after the $1^{\text {st }}$ foreshock.

\section{References}

[1] M. Karaton, H. S. Aksoy, E. Sayın, Y. Calayır, Eng. Fail. Anal., 79, 408-421 (2017)

[2] S. Santis, G. Felice, Proc. Int. Conf. 15 th World Conference on Earthquake Engineering (2012)

[3] J. Kiyono, A. Furukawa, Proc. Int. Conf. 15 th World Conference on Earthquake Engineering (2012)

[4] C. H. Lin, J. Asian. Earth. Sci., 34, 655-662 (2009)

[5] Z. Chang-Hai, Z. Zhi, L. Shuang, X. Li-Li, Soil. Dyn. Earthq. Eng., 74, 46-55 (2015)

[6] J. Ruiz-García, J. C. Negrete-Manriquez, Eng. Struct., 33, 621-634 (2011)

[7] J. Shin, J. S. Jeon, J. H. Kim, Eng. Struct., 165, 315-330 (2018)

[8] S. Zhang,G. Wang, W. Sa, Soil. Dyn. Earthq. Eng., 50, 16-27 (2013)

[9] I. Drygala, J. Dulinska, Ł. Bednarz, J. Jasienko, Key. Eng. Mat., 747, 646-652 (2017)

[10] I. Drygala, J. Dulinska, Ł. Bednarz, J. Jasienko, IOP Conference Series: Materials Science and Engineering (to be published)

[11] ITACA - The Italian Accelerometric Archive, version 2.1. [Internet].

[12] J. Lee, G.L. Fenves, J. Eng. Mech., 124, 892-900 (1998)

[13] A. Wawrzynek, A. Cińcio, Proc. of the $7^{\text {th }}$ International Masonry Conference (2006)

[14] A. Cińcio, Ph.D. Thesis, Silesian Univ. of Technology (2004)

[15] M. Mrożek, Ph.D. Thesis, Silesian Univ. of Technology (2012)

[16] A. Passowicz, D. Norberciak, P., Master Thesis, Poznań Univ. of Technology (2005)

[17] Ł. Bednarz, Ph.D. Thesis, Wrocław Univ. of Science and Technology (2008)

[18] Simulia, ABAQUS/Standard (2013)

[19] J. Jasieńko, Ł.J. Bednarz, W.J. Misztal, K.A. Raszczuk, T.P. Nowak, Proc. of $16^{\text {th }}$ International Brick and Block Masonry Conference (2016)

[20] J. Jasieńko, Ł.J. Bednarz, Proc. of the $8^{\text {th }}$ International Masonry Conference (2010)

[21] Ł.J. Bednarz, J. Jasieńko, M. Rutkowski, T.P. Nowak, Eng. Struct., 81, 62-75 (2014) 